\title{
Tangier Disease
}

\section{HIGH DENSITY LIPOPROTEIN DEFICIENCY DUE TO DEFECTIVE} METABOLISM OF AN ABNORMAL APOLIPOPROTEIN A-I

\author{
(APOA-I TANGIER $)$
}

\author{
Ernst J. Schaefer, Linda L. Kay, Loren A. Zech, and H. Bryan Brewer, Jr., \\ Molecular Disease Branch National Heart, Lung, and Blood Institute; \\ National Institutes of Health, Bethesda, Maryland 20205
}

\begin{abstract}
A B S T R A C T Tangier disease is a rare familial disorder characterized by enlarged orange tonsils, transient peripheral neuropathy, hepatosplenomegaly, and lymphadenopathy, as well as striking reductions in plasma high density lipoproteins (HDL) and their major protein constituents, apolipoproteins (apo)A-I and A-II. In order to test the hypothesis that Tangier patients have abnormal apoA-I or apoA-II, the in vitro lipoprotein binding and in vivo metabolic characteristics of these proteins isolated from normal and Tangier plasma, were studied in normal subjects and patients with Tangier disease.
\end{abstract}

After incubation with normal plasma, significantly greater percentages of radiolabeled Tangier apoA-I were associated with the $1.063-\mathrm{g} / \mathrm{ml}$ supernate $(6 \%)$ and the $1.21 \mathrm{~g} / \mathrm{ml}$ infranate $(19 \%)$, and a lower percentage with HDL (75\%), than those observed for normal apoA-I $(2,8$, and $90 \%$, respectively). In contrast, the lipoprotein binding properties of normal and Tangier apoA-II were very similar. Following the injection of radiolabeled normal and Tangier apoA-I into normal subjects $(n=4)$, the mean residence times of the specific activity for apoA-I $\mathbf{I}_{\text {Tangier }}$ were significantly lower, both in plasma (1.29 d) and in HDL $(1.34 \mathrm{~d})$, than those observed for normal apoA-I (3.80 and 4.06 d). In Tangier homozygotes the decay rates of these tracers were very rapid and were similar. No significant differences between the kinetics of normal and Tangier apoA-II were observed in normal subjects $(n$ $=2$ ).

Tangier homozygotes $(n=3)$ had mean plasma

This work was presented in part at the Annual Meeting of the American Society for Clinical Investigation, Washington, DC, 10 May 1982.

Received for publication 28 December 1981, and in revised form 20 July 1982.
HDL cholesterol, apoA-I, and apoA-II concentrations that were 4,2 , and $11 \%$ of normal $(n=24)$, respectively, whereas for heterozygotes $(n=3)$ these values were 46,62 , and $68 \%$ of normal. In homozygotes, in contrast to normals or heterozygotes, a significant fraction of both apoA-I and apoA-II were found in the $1.063-\mathrm{g} / \mathrm{ml}$ supernate instead of in HDL. Homozygotes had apoA- $\mathrm{I}_{\text {Tangier }}$ synthesis rates and residence times that were 41 and $5 \%$ of values observed for normal apoA-I in normal subjects, and for apoA-II in homozygotes, these parameters were 63 and $18 \%$ of normal. Heterozygotes had apoA-I synthesis rates and residence times that were 92 and $66 \%$ of normal, and for apoA-II these values were 101 and $64 \%$ of normal.

These data are consistent with the concept that apoA-I $\mathrm{I}_{\text {Tangier }}$ is functionally and metabolically distinct from normal apoA-I, and is the cause of the striking hypercatabolism of apoA-I and apoA-II, and the lipoprotein abnormalities observed in Tangier disease.

\section{INTRODUCTION}

Tangier disease was described by Fredrickson et al. (1) in two young siblings from Tangier Island in the Chesapeake Bay. These children presented with enlarged, orange tonsils, mild hepatosplenomegaly, and lymphadenopathy, and subsequently developed mild transient peripheral neuropathy (1-5). Cholesterol-ester laden reticuloendothelial cells have been noted in the bone marrow, tonsils, skin, rectal mucosa, liver, spleen, lymph nodes, and conjunctiva of these patients (1, 5-8). A striking deficiency of high density lipoprotein $(\mathrm{HDL})^{1}$ constituents was found in these subjects

\footnotetext{
'Abbreviations used in this paper: apo, apolipoproteins; HDL, high density lipoproteins; LDL, low density lipoproteins; PAGE, polyacrylamide gel electrophoresis; and VLDL, very low density lipoproteins.
} 
(2-4). The parents of these patients did not share their clinical features, but did have HDL levels that were $\sim 50 \%$ of normal, and therefore were designated as obligate heterozygotes for this autosomal recessive disorder (2-4).

HDL, as isolated from human plasma by ultracentrifugation in the density range of 1.063 to $1.21 \mathrm{~g} / \mathrm{ml}$, consist (weight percent) of $\sim 50 \%$ protein, $25 \%$ phospholipid, $20 \%$ cholesterol, and 5\% triglyceride (9-10). The cholesterol component of HDL has been shown to be inversely correlated with coronary artery disease incidence (11-14). The major protein constituents of HDL are apolipoproteins (apo) A-I and A-II (9, 15, 16), which generally consitute $>90 \%$ of the protein mass of HDL. Tangier homozygotes have plasma HDL cholesterol and apoA-II levels that are $\sim 5-10 \%$ of normal, and apoA-I concentrations that are $1-2 \%$ of normal (17-19). Not only do Tangier homozygotes have markedly decreased apoA-I and apoA-II concentrations, but the distribution of these apolipoproteins among plasma lipoproteins is abnormal. In normal plasma $90 \%$ or more of the mass of each of these apolipoproteins is found within the HDL density region of $1.063-1.21 \mathrm{~g} / \mathrm{ml}(20-22)$; whereas in Tangier plasma, $\sim 80 \%$ of apoA-II and $30 \%$ of apoA-I mass is in the $1.063 \mathrm{~g} / \mathrm{ml}$ supernate, and $\sim 70 \%$ or more of apoA-I is in $1.21 \mathrm{~g} / \mathrm{ml}$ infranate (19).

Tangier homozygotes also have decreased low density lipoprotein (LDL) levels, hypocholesterolemia, hypertriglyceridemia, increased very low density lipoprotein (VLDL) concentrations, and fasting chylomicronemia $(1-4,23)$. It has been suggested that the lipid deposition in homozygotes is due to the uptake of abnormal triglyceride-rich lipoproteins by macrophages $(3,5,24)$. Human lymph chylomicrons contain significant amounts of apoA-I and apoA-II, and these can serve as precursors for plasma HDL apoA-I and apoA-II (25). This conversion process appears to be defective in Tangier homozygotes (26), resulting in rapid and altered apoA-I and apoA-II fractional catabolism, both under steady-state base-line conditions (19), and after HDL infusion $(27,28)$.

The purpose of this study was to define the lipoprotein binding properties and metabolic characteristics of apoA-I and apoA-II, as isolated from both normal and Tangier plasma, in normal subjects as well as Tangier heterozygotes and homozygotes. These investigations were carried out in order to test the hypothesis that Tangier apoA-I and apoA-II are functionally and metabolically abnormal apolipoproteins. The data presented here are consistent with the concept that Tangier apoA-I is functionally and kinetically abnormal, and that the clinical features and lipoprotein abnormalities observed in Tangier disease are due to this abnormal apoA-I (apoA-I $\mathbf{I}_{\text {Tangier }}$ ).

\section{METHODS}

Subjects studied. The age, sex, height, weight, plasma lipid, and lipoprotein cholesterol values for the subjects studied are given in Table I. Mean values $( \pm \mathrm{SD})$ are given for weights and plasma cholesterol and triglyceride concentrations. Weights were determined daily during the course of each study on a metabolic balance, and plasma lipids were measured on all blood samples obtained during the course of each metabolic study. Informed consent was obtained from all subjects, and all studies were performed on a metabolic ward. All subjects had normal hepatic, renal, and thyroid function, and were studied while on an isocaloric, 16$20 \%$ protein, $40-42 \%$ fat (polyunsaturated/saturated fat ratio $0.1: 0.3), 40-42 \%$ carbohydrate, $300-400-\mathrm{mg} / \mathrm{d}$ cholesterol diet. Normal physical activity was permitted, and all subjects were requested to adhere to approximately the same amount of physical activity per day. Subjects were given supersaturated potassium iodide $(0.5-1.0 \mathrm{~g} / \mathrm{d})$ to block thyroid uptake of radioactivity, and ferrous sulfate $(900 \mathrm{mg} / \mathrm{d})$ before and during each metabolic study. The clinical features of the Tangier homozygotes studied have been previously described (1-4, 29). Patients 1 and 2 represent the two original cases as described by Fredrickson et al. (1), and patient 3 was originally described by Hoffman et al. (29). The parents of patients 1 and 2, who are obligate heterozygotes (1-3), were also studied, as was the sister of patient 3 (29).

Quantitation and isolation of plasma lipids, lipoproteins, and apolipoproteins. Plasma lipid and lipoprotein cholesterol values were measured by established Lipid Research Clinics Methodology using the Autoanalyzer II $(30,31)$. Mean values $( \pm \mathrm{SD})$ for normal subjects $(n=1,088)$ as measured in our laboratory are: total cholesterol $189 \pm 0 \mathrm{mg} / \mathrm{dl}$, triglyceride $87 \pm 43 \mathrm{mg} / \mathrm{dl}$, VLDL cholesterol $16 \pm 11 \mathrm{mg} / \mathrm{dl}$, LDL cholesterol $123 \pm 35 \mathrm{mg} / \mathrm{dl}$, and HDL cholesterol $50 \pm 14$ $\mathrm{mg} / \mathrm{dl}(32)$.

HDL were isolated by ultracentrifugation at $d$ 1.063-1.21 $\mathrm{g} / \mathrm{ml}$ using $\mathrm{KBr}$ for density adjustments as previously described $(10,33)$ in Beckman L265B ultracentrifuges (Beckman Instruments, Inc., Fullerton, CA). The protein content in HDL was determined by the method of Lowry et al. (34), the phospholipid content by the method of Chalvardjian et al. (35), and the cholesterol and triglyceride content by Autoanalyzer II methodology following Folch extraction (36). ApoA-I and apoA-II concentrations in plasma, $1.063 \mathrm{~g} / \mathrm{ml}$ supernate, and HDL samples were determined by radial immunodiffusion (21). All samples were delipidated with methanol/diethyl ether (3:7), and the protein resolubilized in 0.05 M sodium barbital, $8 \mathrm{mM}$ sodium azide, $\mathrm{pH} 8.3$ for immunochemical measurement. Purified apoA-I and apoA-II standards were used for each radial immunodiffusion plate, and the protein concentration of standards was determined by amino acid analysis on a Beckman model 121 Automatic Amino Acid Analyzer. Plasma and HDL fractions were diluted 1:15 for apoA-I determinations, and 1:5 for apoA-II measurements in normal and heterozygotes. The $1.063-\mathrm{g} / \mathrm{ml}$ supernate and all samples from homozygotes were run undiluted. Standard curves for apoA-I were linear over a concentration range from 0.25 to $16.0 \mathrm{mg} / \mathrm{dl}$ and for apoA-II over a range from 0.5 to $10.0 \mathrm{mg} / \mathrm{dl}$. Samples from homozygotes were also run on electroimmunoassay apoA-I and apoA-II, and these results gave very good agreement to those obtained by radial immunodiff usion $(20,28)$.

ApoA-I and apoA-II were isolated by column chromatography from HDL $(1.09-1.21 \mathrm{~g} / \mathrm{ml})$ as previously described $(37,38)$. ApoA-I was isolated from Tangier plasma (patient 
TABLE I

Subjects Studied ${ }^{\bullet}$

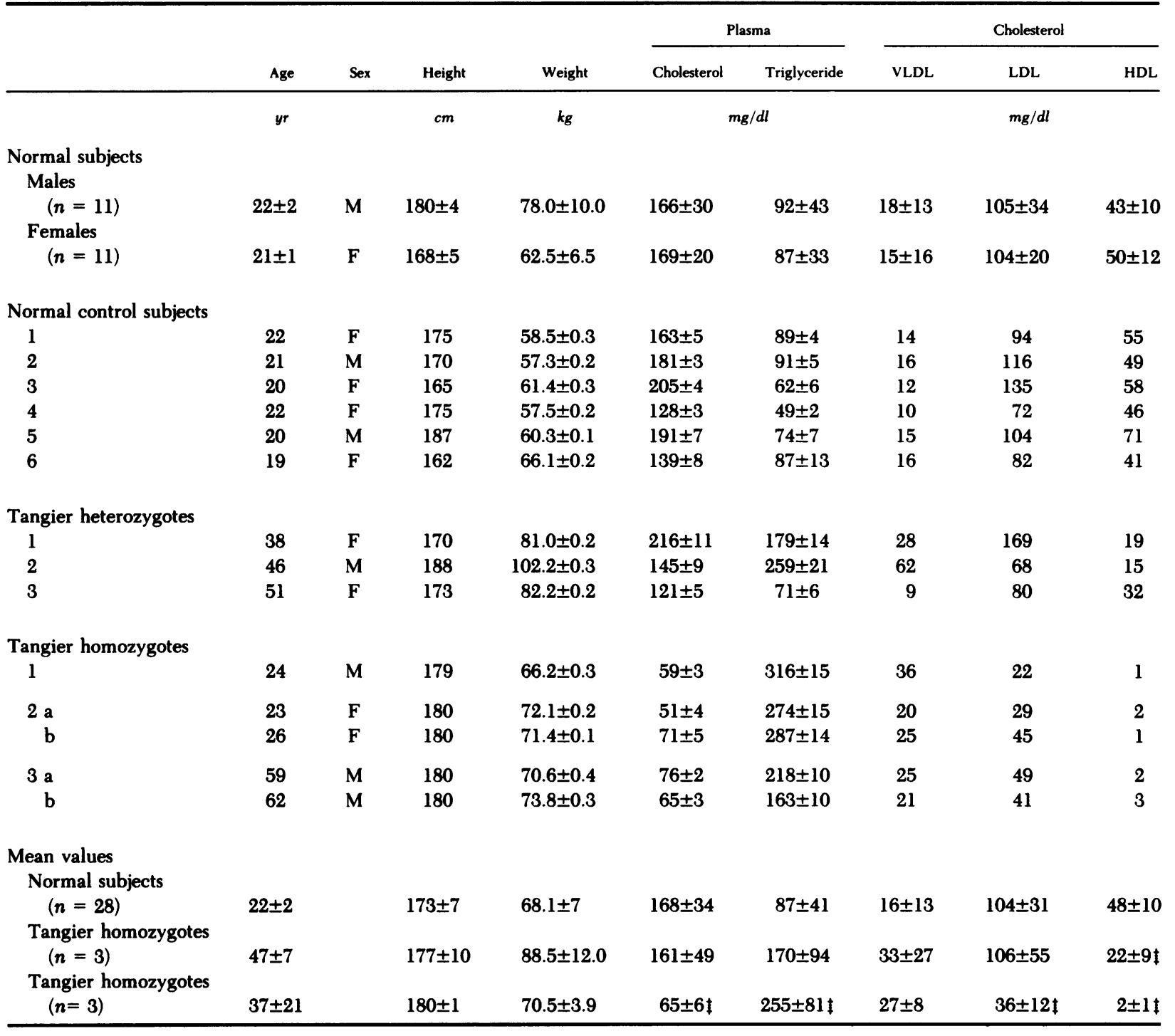

- Mean values $\pm \mathrm{SD}$, weight and plasma lipids were determined daily during the course of each study, and lipoprotein cholesterol values were measured at the beginning of each study. Normal control subjects are those who were studied with both normal and Tangier radiolabeled apolipoprotein.

† Significantly $(P<0.01)$ different from normal $(t$ test analysis).

1) from the $1.21-\mathrm{g} / \mathrm{ml}$ supernate by preparative sodium dodecyl sulfate (SDS) polyacrylamide gel electrophoresis (PAGE) $(0.1 \%$ SDS, $15 \%$ acrylamide, $0.05 \%$ bis, $0.552 \%$ cross linkage [39]). The SDS was subsequently removed from the protein by electrophoresis, using an ISCO Electrophoretic Sample Concentrator, model 750 (Instrumentation Specialties Co., Lincoln, NE). ApoA-I was isolated from normal plasma in identical fashion for purposes of comparison with Tangier ApoA-I. ApoA-II was isolated from Tangier plasma (patient 1) from the $1.21-\mathrm{g} / \mathrm{ml}$ supernate by column chromatography (38). ApoA-II was also isolated from normal plasma in identical fashion for purposes of comparison.
Radioiodination of apolipoproteins. All apoA-I and apoA-II preparations used for radioiodination formed discrete bounds on SDS PAGE (40). Apolipoproteins formed a line of immunoprecipitation only against their own respective antisera when tested with antisera for apoA-I, apoA-II, apoB, apoC-II, apoC-III, apoE, and albumin. ApoA-I and apoA-II were iodinated with ${ }^{125} \mathrm{I}$ or ${ }^{131} \mathrm{I}$ (New England Nuclear, Boston, MA) at a mean protein concentration of $3.6 \pm 1.1 \mathrm{mg} / \mathrm{ml}$ in sterile $1 \mathrm{M}$ glycine, $0.1 \mathrm{M}$ Tris, $\mathrm{pH} 8.5$ buffer, by the iodine monochloride method of McFarlane (39). For all radiolabeled preparations the efficiency of iodination was assessed by precipitation of protein with $20 \%$ 
trichloroacetic acid (TCA) following a 1:1 dilution with 5\% bovine serum albumin solution. Unbound iodine was removed by extensive dialysis against sterile $0.85 \% \mathrm{NaCl}$, $0.01 \%$ EDTA, $0.1 \mathrm{M}$ Tris, $\mathrm{pH} 7.4$ solution. The percentage of free iodine present in radiolabeled preparations after dialysis was assessed by precipitation of protein with $20 \%$ TCA, and was also measured by descending strip paper radiochromatography (85\% methanol on Whatman number 1 filter paper, Whatman Co., Clifton, NJ) utilizing a Packard model 7201 radiochromatogram scanner (Packard Instrument Co., Inc., Downers Grove, IL).

Radiolabeled preparations were subjected to SDS PAGE with unlabeled apo standard to ascertain the location of radioactivity on PAGE. All preparations were diluted 1:10 with sterile $5 \%$ human albumin solution to minimize radiation damage, were subjected to Millipore (Millipore Corp., Bedford, MA) filtration (0.22 micron filter), and tested for pyrogenicity and sterility before use. For single isotope studies a mean of $84 \pm 7 \mu \mathrm{Ci}$ of ${ }^{125} \mathrm{I}$ were used, and for double isotope studies a mean of $87 \pm 5$ of ${ }^{125} \mathrm{I}$ and $23 \pm 9 \mu \mathrm{Ci}$ of ${ }^{131} \mathrm{I}$ were injected intravenously. A mean of $0.2 \pm 0.1 \mathrm{mg}$ of labeled apoprotein in a mean volume of $0.8 \pm 0.3 \mathrm{ml}$ were injected intravenously in tracer studies. Radiolabeled HDL was isolated and labeled with ${ }^{125} \mathrm{I}$ as previously described (19).

Metabolic studies. 26 normal male and female subjects, 3 Tangier heterozygotes, and 3 Tangier homozygotes were studied. Six normal male subjects, eight normal female subjects, one heterozygote and all three homozygotes simultaneously received normal radiolabeled apoA-I and apoA-II. Three normal males and one normal female subject received normal radiolabeled apoA-I only, and two normal males received normal radiolabeled apoA-II only. One normal male, three normal females, and two Tangier homozygotes (patients 2 and 3 ) simultaneously received ${ }^{125}$ I Tangier apoA-I and ${ }^{131} I$ normal apoA-I. One normal male and one normal female subject simultaneously received ${ }^{125}$ I Tangier apoA-II and ${ }^{131}$ I normal apoA-II. Tracer studies in normal subjects and heterozygotes were of 13-21 d duration (in most cases $14 \mathrm{~d}$ ) and in Tangier homozygotes were of $7 \mathrm{~d}$ duration. Radiolabeled autologous HDL studies in eight normal controls, and two heterozygotes were performed as previously described (19).

In all metabolic studies blood was obtained in $0.1 \%$ EDTA just before injection of radioactivity, at $10 \mathrm{~min}, 6 \mathrm{~h}$, and 12 $h$ after injection, and then daily for the duration of the study. In homozygotes blood samples were also obtained 3 and 6 $\mathrm{h}$ after injection. Plasma was separated from blood at $4^{\circ} \mathrm{C}$ in a refrigerated centrifuge. HDL $(1.063-1.21 \mathrm{~g} / \mathrm{ml})$ was isolated as previously described from plasma obtained just before injection, and at $6 \mathrm{~h}, 12 \mathrm{~h}$, and days $1,4,7,10$, and 13 , or 14 after injection. In homozygotes HDL was also isolated at 3 and $9 \mathrm{~h}$ after injection, but not on days 10,13 , or 14. Radioactivity in plasma, $1.063 \mathrm{~g} / \mathrm{ml}$ supernate, HDL, and $1.21 \mathrm{~g} / \mathrm{ml}$ infranate was determined utilizing a Packard model 5260 Autogamma Counter Spectrometer.

Lipoprotein binding studies and column chromatography. Radiolabeled apo (1-2 $\mu \mathrm{l})$ were incubated with 5-ml aliquots of plasma (normal or Tangier plasma) for $30 \mathrm{~min}$ at $37^{\circ} \mathrm{C}$ in a shaking water bath. Aliquots were subjected to ultracentrifugation for the isolation of HDL (1.063-1.21 g/ $\mathrm{ml}$ ) as previously described. In addition $5-\mathrm{ml}$ plasma aliquots were subjected to gel permeation chromatography with 100 $\times 1.2 \mathrm{~cm}$ columns (Kontes Glass Co., Vineland, $\mathrm{NJ}$ ) of Sepharose 6B-Cl (Pharmacia Fine Chemicals, Div. Pharmacia, Inc., Piscataway, $\mathrm{NJ}$ ) in $0.85 \% \mathrm{NaCl}, 0.01 \%$ EDTA, $1 \mathrm{mM}$ sodium azide, pH 7.4 buffer at room temperature $\left(24^{\circ} \mathrm{C}\right)$. Sample volumes applied to the column were $5 \mathrm{ml}$ and flow rates were $\sim 15 \mathrm{ml} / \mathrm{h}$. Preparations of $\mathrm{HDL}_{2 \mathrm{~b}}(1.063-1.10$ $\mathrm{g} / \mathrm{ml}), \mathrm{HDL}_{2 \mathrm{a}+3}(1.10-1.21 \mathrm{~g} / \mathrm{ml})$ and $1.063 \mathrm{~g} / \mathrm{ml}$ supernate applied to this column were isolated from a normolipemic individual by ultracentrifugation as previously described.

Calculation of apolipoprotein kinetic parameters and statistical analysis. Specific radioactivity decay curves within plasma, HDL (in normals), and the $1.063 \mathrm{~g} / \mathrm{ml}$ supernate (in homozygotes) were fit utilizing the SAAM simulator (41) on a VAX 11/780 computer (Digital Equipment Co., Maynard, MA). Curves required three exponentials for adequate curve fitting (fractional standard deviation $\leq 0.1$ ), and residence times ( $1 /$ fractional catabolic rate) were obtained from the area under the curve (42). Apolipoprotein synthesis rates (SR) were calculated utilizing the formula:

$\mathrm{SR}=$ (plasma volume) (plasma apolipoprotein concentration)/

(plasma apolipoprotein residence time) (body weight).

Student's $t$ test was used to ascertain significant differences between sets of data.

\section{RESULTS}

Plasma lipid and lipoprotein data. Plasma lipid and lipoprotein cholesterol concentrations on all study subjects are given in Table I. Normal females had significantly higher $(P<0.01)$ HDL cholesterol and slightly lower VLDL cholesterol and triglyceride levels than did normal males. Tangier homozygotes had significantly $(P<0.01)$ lower plasma cholesterol, LDL cholesterol, and HDL cholesterol values, and higher VLDL cholesterol and triglyceride values than did normal subjects. Tangier heterozygotes had HDL cholesterol levels that were $\sim 50 \%$ of normal $(P<0.01)$. Compositional data on HDL $(1.063-1.21 \mathrm{~g} / \mathrm{ml})$ in study subjects are shown in Table II. Normal female subjects had significantly $(P<0.01)$ higher HDL protein, phospholipid, and cholesterol concentrations than did normal males. Tangier heterozygotes had reductions in all these HDL constituents, and homozygotes, as expected, had even more striking deficiencies of HDL components.

Characterization of radioiodinated apolipoproteins. The mean efficiencies of iodination for normal apoA-I and apoA-II preparations were $53.6 \pm 7.1 \%$ and $62.4 \pm 9.2 \%$, respectively, and for Tangier apoA-I and apoA-II preparations were $39.2 \pm 1.1 \%$ and $73.5 \pm 0.9 \%$, respectively. Assuming a molecular weight of 28,000 for apoA-I, and 18,000 for apoA-II, a mean of $0.6 \pm 0.2$ mol of iodine $/ \mathrm{mol}$ of protein was incorporated into normal apoA-I during iodination, and for normal apoA-II $0.9 \pm 0.1$. For Tangier apoA-I and apoA-II these values were $0.5 \pm 0.1$ and $0.9 \pm 0.1$, respectively. All radioiodinated apo preparations contained no free iodine by radiochromatography, and $<1 \%$ by TCA precipitation, and were sterile and pyrogen-free.

The distributions of apoA-I and apoA-II radioactivity among plasma lipoproteins for both normal and Tangier plasma after ultracentrifugation are shown in 
TABLE II

HDL Composition ${ }^{\circ}$

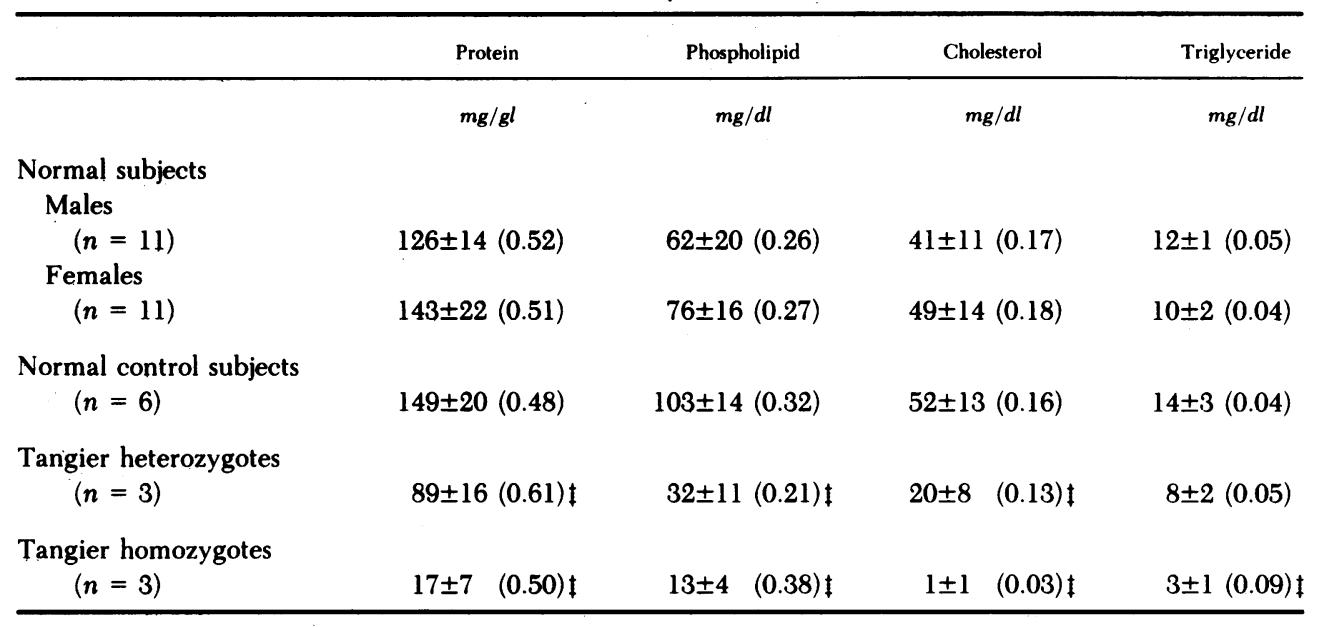

- Mean values $\pm \mathrm{SD}$, represents the mean of seven $\mathrm{HDL}(d 1.063-1.21 \mathrm{~g} / \mathrm{ml})$ isolations from fasting normal and Tangier heterozygotes, and four HDL $(d 1.063-1.21 \mathrm{~g} / \mathrm{ml})$ isolations in homozygotes. Values in parenthesis indicate the fraction of total for each subject. The kinetics of radiolabeled normal and Tangier apoA-I or normal and Tangier apoA-II were studied in normal control subjects.

f Significantly $(P<0.01)$ different from normal $(t$ test analysis $)$.

Table III. The data is given for in vivo plasma samples (10 min after injection). In vitro distributions were very similar to in vivo results in all cases. No significant change in the distributions of radioactivity among lipoprotein fractions was noted throughout the course of any study. A significantly $(P<0.01)$ higher percentage of Tangier apoA-I radioactivity was associated with the $1.063-\mathrm{g} / \mathrm{ml}$ supernate and the $1.21-\mathrm{g} / \mathrm{ml}$ infranate than that seen for normal apoA-I radioactivity in normal plasma. Such differences were not observed for Tangier plasma; however much higher percentages of both normal and Tangier apoA-I radioactivity were associated with both the $1.063-\mathrm{g} / \mathrm{ml}$ supernate and the $1.21 \mathrm{-g} / \mathrm{ml}$ infranate than that observed in normal plasma. The distributions of normal and Tangier apoAII radioactivity among normal plasma lipoproteins were very similar. Similar data were obtained when normal and Tangier radiolabeled apoA-I and apoA-II were incubated with plasma $\left(30 \mathrm{~min}, 37^{\circ} \mathrm{C}\right)$, and then subjected to Sepharose $6 \mathrm{~B}$ column chromatography. When normal and Tangier radiolabeled apoA-I and apoA-II along with unlabeled apoprotein standard were run on SDS PAGE, $>90 \%$ of the radioactivity could be recovered in the appropriate gel band.

Apolipoprotein metabolic parameters. Apo A-I and A-II metabolic parameters are shown in Table IV. Normal female subjects had significantly $(P<0.01)$ higher apoA-I levels and slightly higher apoA-II levels than did males. Normal female subjects had significantly $(P<0.05)$ higher apoA-I and apoA-II synthesis rates than did normal males. In paired studies in nor- mal subjects $(n=14)$ the mean $(4.46 \pm 1.04 \mathrm{~d})$ apoAI plasma residence time was significantly $(P<0.01)$ shorter than that of apoA-II $(4.97 \pm 1.06 \mathrm{~d})$.

Similar data were obtained following the injection of autologous radiolabeled HDL in eight normal subjects (19). In these studies the mean ( \pm SD) apoA-I specific activity residence time within HDL $(4.24 \pm 0.51$ d) was significantly $(P<0.01)$ lower than that of apoAII $(4.83 \pm 0.75 \mathrm{~d})$. The methodology and details of these studies have been previously reported (19) but the apoA-I and apoA-II specific activity within HDL were never assessed by multiexponential curve fitting techniques.

Heterozygotes had apoA-I and apoA-II plasma levels that were significantly lower than normal (see Table IV). In normal subjects and heterozygotes $\sim 90 \%$ of both plasma apoA-I and apoA-II were found within the HDL $(d 1.063-1.21 \mathrm{~g} / \mathrm{ml})$ density region. Heterozygotes, who received either radiolabeled HDL or apo had decreased apoA-I and apoA-II residence times, with relatively normal synthesis rates.

Tangier homozygotes had significantly lower plasma apoA-I and apoA-II concentrations than did normal subjects. A mean of $32.4 \pm 3.1 \%$ of plasma apoA-I mass and $83.5 \pm 5.7 \%$ of plasma apoA-II mass were associated with the $1.063-\mathrm{g} / \mathrm{ml}$ supernate fraction in homozygotes $(n=3)$, similar to the distribution noted for radiolabeled apoA-I and apoA-II (see Table III). After the injection of normal radiolabeled apoA-I and apoAII into homozygotes $(n=3)$, the specific activity decay of these tracers was significantly faster than that seen 
TABLE III

Percent Radioactivity among Lipoprotein Fractions ${ }^{\circ}$

\begin{tabular}{|c|c|c|c|c|c|c|c|c|c|c|c|c|}
\hline & \multicolumn{3}{|c|}{ ApoA-I } & \multicolumn{3}{|c|}{ ApoA-I } & \multicolumn{3}{|c|}{ ApoA-II } & \multicolumn{3}{|c|}{ ApoA-II Then } \\
\hline & $1.063 \mathrm{~T}$ & HDL & $1.21 \mathrm{~B}$ & $1.063 \mathrm{~T}$ & HDL & $1.21 \mathrm{~B}$ & $1.063 \mathrm{~T}$ & HDL & $1.21 \mathrm{~B}$ & $1.063 \mathrm{~T}$ & HDL & $1.21 \mathrm{~B}$ \\
\hline \multicolumn{13}{|l|}{ Normal subjects } \\
\hline$(n=11)$ & 2.64 & 91.43 & 5.93 & - & - & - & 0.61 & 95.30 & 4.09 & - & - & - \\
\hline \multicolumn{13}{|l|}{ Females } \\
\hline$(n=11)$ & 1.82 & 91.70 & 6.48 & - & - & - & 0.32 & 95.01 & 4.67 & - & - & - \\
\hline \multicolumn{13}{|c|}{ Normal control subjects } \\
\hline 1 & 1.81 & 90.85 & 7.33 & 4.03 & 72.98 & 22.99 & - & - & - & - & - & - \\
\hline 2 & 1.44 & 91.41 & 7.15 & 5.55 & 76.47 & 17.97 & - & - & - & - & - & - \\
\hline 3 & 2.10 & 89.68 & 8.22 & 9.77 & 75.03 & 15.20 & - & - & - & - & - & - \\
\hline 4 & 1.93 & 89.74 & 8.33 & 4.75 & 76.80 & 18.45 & - & - & - & - & - & - \\
\hline 5 & - & - & - & - & - & - & 0.17 & 95.21 & 4.62 & 0.69 & 94.98 & 4.33 \\
\hline 6 & - & - & - & - & - & - & 0.51 & 94.89 & 4.60 & 0.54 & 94.27 & 5.19 \\
\hline \multicolumn{13}{|c|}{ Tangier heterozygotes } \\
\hline 3 & 0.41 & 91.21 & 8.35 & - & - & - & 0.20 & 95.61 & 4.19 & & & \\
\hline \multicolumn{13}{|c|}{ Tangier homozygotes } \\
\hline 1 & 31.44 & 15.14 & 53.42 & - & - & - & 83.94 & 6.83 & 9.23 & - & - & - \\
\hline $2 \mathrm{a}$ & 31.21 & 21.20 & 47.59 & - & - & - & 81.62 & 11.63 & 6.75 & - & - & - \\
\hline b & 28.65 & 14.91 & 56.44 & 38.58 & 19.44 & 41.98 & - & - & - & - & - & - \\
\hline $3 \mathbf{a}$ & 25.22 & 16.71 & 58.07 & - & - & - & 79.52 & 10.94 & 9.54 & - & - & - \\
\hline b & 22.82 & 17.38 & 59.79 & 32.86 & 20.18 & 46.96 & - & - & - & - & - & - \\
\hline \multicolumn{13}{|l|}{ Mean values } \\
\hline \multicolumn{13}{|l|}{ Normal control } \\
\hline subjects & 1.82 & 90.42 & 7.76 & $6.03 t$ & $75.32 \ddagger$ & $18.65 \ddagger$ & 0.34 & 95.05 & 4.61 & 0.62 & 94.62 & 4.76 \\
\hline \multicolumn{13}{|l|}{ Tangier } \\
\hline heterozygotes & 0.41 & 91.21 & 8.38 & & & & 0.20 & 95.61 & 4.19 & - & - & - \\
\hline \multicolumn{13}{|l|}{ Tangier } \\
\hline homozygotes & 27.87 & 17.07 & 55.06 & 35.72 & 19.81 & 44.47 & 81.69 & 9.80 & 8.51 & - & - & - \\
\hline
\end{tabular}

- Mean values based on in vivo plasma obtained $10 \mathrm{~min}$ after injection of tracers. 1.063 top is the $1.063-\mathrm{g} / \mathrm{ml}$ supernate, HDL is the $1.063-1.21-\mathrm{g} / \mathrm{ml}$ fraction, and the $1.21 \mathrm{~B}$ is the $1.21-\mathrm{g} / \mathrm{ml}$ infranate.

† Significantly $(P<0.01)$ different from normal apoA-I radioactivity $(t$ test analysis).

in normal subjects, and as in normals, apoA-I was degraded at a faster rate than apoA-II (see Fig. 1). Not only did Tangier homozygotes have enhanced fractional catabolism of apoA-I and apoA-II, but apoA-I and apoA-II synthesis was somewhat reduced in them as well (Table IV).

When normal and Tangier radiolabeled apoA-I were injected into normal subjects, the specific radioactivity decay in both plasma and HDL was significantly faster for the Tangier apoA-I than for normal apoA-I, as shown in Fig. 2 and Table V. However in Tangier homozygotes the specific radioactivity decay of these two tracers in both plasma and the $1.063-\mathrm{g} / \mathrm{ml}$ supernate was similar (see Fig. 3 and Table V). Therefore, kinetic parameters in homozygotes were very similar regardless of which tracer was used. After the injection of normal and Tangier radiolabeled apoA-II, no significant difference in specific radioactivity decay. of these two tracers was noted in either plasma or HDL in two normal subjects (see Fig. 4 and Table V).

\section{DISCUSSION}

Plasma lipid and lipoprotein compositional data, as presented in Tables I and II, are consistent with previous observations that Tangier homozygotes have hypocholesterolemia, mild hypertriglyceridemia, decreased LDL levels, and a striking deficiency of HDL 
TABLE IV

Kinetic Parameters ${ }^{\circ}$

\begin{tabular}{|c|c|c|c|c|c|c|}
\hline & \multicolumn{2}{|c|}{ Plasma concentration } & \multicolumn{2}{|c|}{ Synthesis rate } & \multicolumn{2}{|c|}{ Residences times } \\
\hline & ApoA-I & ApoA-II & ApoA-I & ApoA-II & ApoA-I & ApoA-II \\
\hline & \multicolumn{2}{|c|}{$m g / d l$} & \multicolumn{2}{|c|}{$m g / k g / d$} & \multicolumn{2}{|c|}{$d$} \\
\hline \multicolumn{7}{|l|}{ Normal subjects } \\
\hline \multicolumn{7}{|l|}{ Males } \\
\hline$(n=11)$ & $108 \pm 16$ & $23 \pm 3$ & $11.12 \pm 1.92$ & $2.10 \pm 0.32$ & 4.51 & $5.33 \pm 1.07$ \\
\hline \multicolumn{7}{|l|}{ Females } \\
\hline$(n=9)$ & $124 \pm 24$ & $25 \pm 3$ & $13.58 \pm 2.23$ & $2.52 \pm 0.46$ & 4.18 & $4.56 \pm 0.79$ \\
\hline \multicolumn{7}{|l|}{ Normal control subjects } \\
\hline 1 & $127 \pm 13$ & - & 14.30 & - & 3.82 & - \\
\hline 2 & $124 \pm 13$ & - & 12.02 & - & 4.54 & - \\
\hline 3 & $131 \pm 5$ & - & 16.73 & - & 3.21 & - \\
\hline 4 & $108 \pm 5$ & - & 13.10 & - & 3.63 & - \\
\hline 5 & - & $31 \pm 1$ & - & 2.34 & - & 5.83 \\
\hline 6 & - & $28 \pm 2$ & - & 3.07 & - & 4.11 \\
\hline \multicolumn{7}{|l|}{ Tangier heterozygotes } \\
\hline 1 & $73 \pm 3$ & $17 \pm 1$ & $13 . \ddot{48}$ & 2.65 & 2.22 & 2.63 \\
\hline 2 & $61 \pm 5$ & $14 \pm 2$ & 10.52 & 2.29 & 2.61 & 2.75 \\
\hline 3 & $84 \pm 1$ & $19 \pm 2$ & 10.85 & 2.14 & 3.56 & 4.09 \\
\hline \multicolumn{7}{|l|}{ Tangier homozygotes } \\
\hline 1 & $1.9 \pm 0.3$ & $2.7 \pm 0.4$ & 4.25 & 1.52 & 0.21 & 0.83 \\
\hline 2 a & $1.8 \pm 0.4$ & $2.8 \pm 0.7$ & - & 1.61 & 0.22 & 0.81 \\
\hline b & $1.9 \pm 0.2$ & - & 5.03 & - & 0.17 & \\
\hline $3 a$ & $2.8 \pm 0.2$ & $3.0 \pm 0.4$ & & 1.27 & 0.27 & 1.06 \\
\hline b & $3.0 \pm 0.2$ & - & 5.33 & - & 0.27 & \\
\hline \multicolumn{7}{|l|}{ Mean values $\pm S D$} \\
\hline Normal control subjects & $117 \pm 17$ & $25 \pm 3$ & $12.60 \pm 2.38$ & $2.34 \pm 0.46$ & $4.26 \pm 0.99$ & $4.95 \pm 0.99$ \\
\hline Tangier heterozygotes & $73 \pm 12 \ddagger$ & $17 \pm 3 \ddagger$ & $11.62 \pm 1.62$ & $2.36 \pm 0.26$ & $2.80 \pm 0.69 \rrbracket$ & $3.16 \pm 0.81 \ddagger$ \\
\hline Tangier homozygotes & $2.3 \pm 0.6 t$ & $2.8 \pm 0.2 \downarrow$ & 5.18 & $1.47 \pm 0.18 \ddagger$ & 0.22 & $0.90 \pm 0.14\rceil$ \\
\hline
\end{tabular}

- Heterozygotes 1 and 2 had radiolabeled HDL studies and other subjects had radiolabeled apolipoprotein studies. Homozygotes 1-3 were studied with normal radiolabeled apoA-I and apoA-II, while homozygotes 2 and 3 were also studied with radiolabeled apoA-I ${ }_{\text {Tangier }}$ (study b). Mean ApoA-I parameters in Tangier homozygotes are reported for apoA- $\mathrm{I}_{\text {Tangier }}$ studies only. Mean values are given \pm SD. $\ddagger$ Significantly $(P<0.01)$ different from normal.

$(1-4,18,19)$. The striking reductions in plasma apoAI and apoA-II as observed in homozygotes are consistent with previous studies $(17-19,27,28,43)$. Homozygotes do not appear to have significant deficiencies of other apolipoproteins (43). The only HDL constituent not greatly reduced in homozygotes was HDL triglyceride. Tangier heterozygotes had normal LDL levels, moderate increases in VLDL, and reduced HDL levels as previously reported (2-4).

Radiolabeled normal apoA-I and apoA-II radioactivity was found mainly in the HDL density region after injection of these tracers into normal subjects.
Ultracentrifugation and column chromatography data were in good agreement. The distribution of these tracers among plasma lipoproteins was very similar to the mass distribution of apoA-I and apoA-II, consistent with the concept that these apolipoproteins can readily exchange among plasma lipoproteins $(10,44)$. When normal radiolabeled apoA-I and apoA-II were injected into Tangier homozygotes, $\sim 80 \%$ of apoA-II radioactivity and $30 \%$ of apoA-I radioactivity were associated with the $1.063-\mathrm{g} / \mathrm{ml}$ supernate, and $\sim 50 \%$ of apoA-I radioactivity was found in the $1.21-\mathrm{g} / \mathrm{ml}$ infranate; also consistent with the mass distribution of 


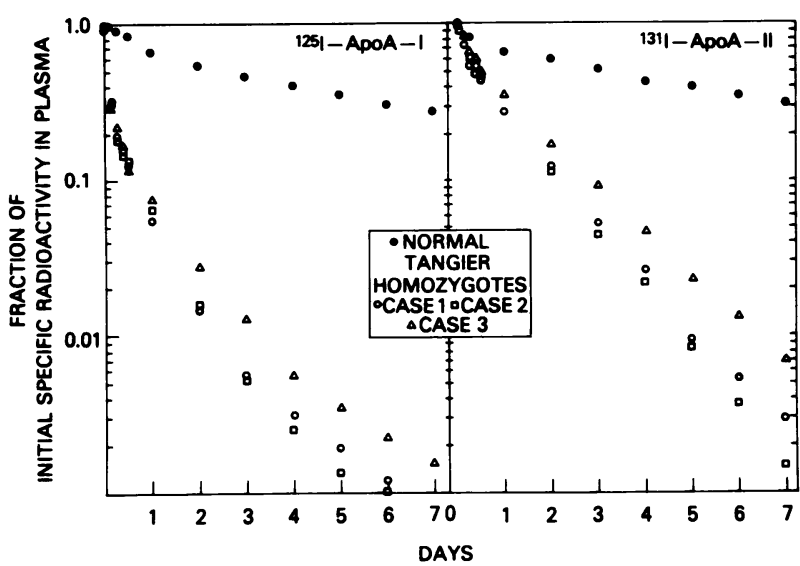

FigURE 1 Specific radioactivity decay curves for normal ${ }^{125}$ I apoA-I (left panel) and ${ }^{131} I$ apoA-II (right panel) in a normal subject $(\odot)$ and three Tangier homozygotes $(O, \square, \Delta)$.

these apolipoproteins in Tangier plasma noted in these experiments, as well as previously $(19,28)$. Tangier apoA-II radioactivity distribution among plasma lipoproteins in both normal and Tangier plasma was very similar to that obtained with normal radiolabeled apoA-II. In contrast, in both normal and Tangier plasma, greater percentages of Tangier apoA-I radioactivity were found in the $1.063-\mathrm{g} / \mathrm{ml}$ supernate and the $1.21 \mathrm{-g} / \mathrm{ml}$ infranate (for normal plasma) as compared with normal apoA-I. These data are consistent with the concept that the binding of Tangier apoA-II to plasma lipoproteins is identical to normal apoA-II, but that Tangier apoA-I has somewhat different lipoprotein binding characteristics than normal apoA-I.

Apolipoprotein kinetic data obtained with normal radiolabeled apoA-I and apoA-II are consistent with previously reported observations that Tangier homozygotes have strikingly enhanced and disparate apoA$I$ and apoA-II fractional catabolic rates, both in the steady state (19), and after HDL infusion $(27,28)$. This rapid catabolism was seen in both whole plasma and the $1.063-\mathrm{g} / \mathrm{ml}$ infranate. Our studies also indicate that Tangier homozygotes have somewhat reduced apoAI (as determined by radiolabeled Tangier apoA-I tracer studies) and apoA-II synthesis rates.

In normal subjects the specific radioactivity decay of Tangier apoA-I was significantly faster than that of normal apoA-I in both plasma and HDL. Recent observations from our laboratory have demonstrated that Tangier apoA-I has a slightly higher molecular weight on SDS PAGE, greater isoform heterogeneity, and different amino acid composition than normal apoA-I, whereas Tangier and normal apoA-II were virtually identical in these respects (45). Zannis et al. (46) have recently reported that, on two dimensional gel electrophoresis of plasma, Tangier homozygotes have increased proportions of the plasma apoA-I isoforms apoA-I $\mathrm{I}_{2}$ and apoA-I $\mathrm{I}_{3}$, considered to be precursor apoAI isoforms (47), while normal subjects have mainly

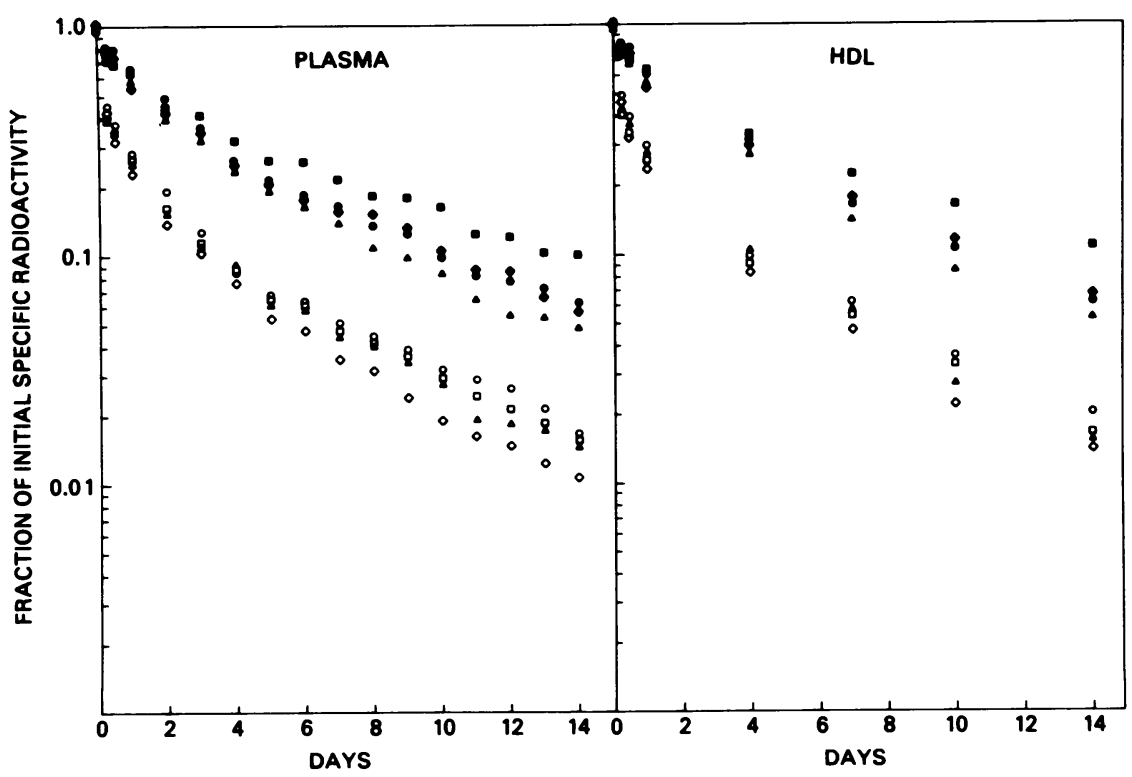

FIgURE 2 Specific radioactivity decay in plasma (left panel) and HDL $(d, 1.063-1.21 \mathrm{~g} / \mathrm{ml}$, right panel) of ${ }^{125} \mathrm{I}$ apoA-I Tangier (open symbols) and ${ }^{131} \mathrm{I}$ apoA-I (closed symbols) in four normal control subjects (cases 1-4). 
TABLE V

Specific Radioactivity Residence Times (Days) ${ }^{\circ}$

\begin{tabular}{|c|c|c|c|c|c|c|c|c|c|c|}
\hline & \multicolumn{3}{|c|}{ ApoA-I } & \multicolumn{3}{|c|}{ ApoA-I Tander $_{\text {The }}$} & \multicolumn{2}{|c|}{ ApoA-II } & \multicolumn{2}{|c|}{ ApoA-II Tangler } \\
\hline & Plasma & $1.063 \mathrm{~T}$ & HDL & Plasma & $1.063 \mathrm{~T}$ & HDL & Plasma & HDL & Plasma & HDL \\
\hline \multicolumn{11}{|l|}{ Normal control subjects } \\
\hline 1 & $3.82 \pm 0.03$ & - & $3.96 \pm 0.03$ & $1.40 \pm 0.02$ & - & $1.48 \pm 0.03$ & - & - & - & - \\
\hline 2 & $4.54 \pm 0.02$ & - & $4.73 \pm 0.03$ & $1.23 \pm 0.01$ & - & $1.27 \pm 0.02$ & - & - & - & - \\
\hline 3 & $3.21 \pm 0.02$ & - & $3.75 \pm 0.04$ & $1.41 \pm 0.08$ & - & $1.44 \pm 0.03$ & - & - & - & - \\
\hline 4 & $3.63 \pm 0.02$ & - & $3.81 \pm 0.02$ & $1.10 \pm 0.02$ & - & $1.16 \pm 0.02$ & - & - & - & - \\
\hline 5 & - & - & - & - & & - & $5.83 \pm 0.05$ & $6.24 \pm 0.04$ & $5.54 \pm 0.04$ & $6.12 \pm 0.04$ \\
\hline 6 & - & - & - & - & & - & $4.11 \pm 0.06$ & $3.97 \pm 0.05$ & $3.58 \pm 0.05$ & $3.64 \pm 0.04$ \\
\hline \multicolumn{11}{|l|}{ Tangier homozygotes } \\
\hline $2 b$ & $0.14 \pm 0.04$ & $0.14 \pm 0.11$ & - & $0.17 \pm 0.04$ & $0.17 \pm 0.10$ & - & - & - & - & - \\
\hline $3 \mathbf{b}$ & $0.21 \pm 0.03$ & $0.21 \pm 0.03$ & - & $0.27 \pm 0.03$ & $0.25 \pm 0.03$ & - & - & - & - & - \\
\hline \multicolumn{11}{|l|}{ Mean values \pm SD } \\
\hline Normal control subjects & $3.80 \pm 0.56$ & - & $4.06 \pm 0.45$ & $1.29 \pm 0.15 !$ & - & $1.34 \pm 0.15 t$ & 4.97 & 5.11 & 4.56 & 4.88 \\
\hline Tangier homozygotes & 0.18 & 0.18 & - & 0.22 & 0.21 & - & - & - & - & - \\
\hline
\end{tabular}

- The residence times of the specific activity decay are given \pm fractional standard deviation. The mean values for normal control are given $\pm \mathrm{SD}$. t Significantly $(P<0.01)$ different from normal ( $t$ test analysis).

apoA-I $I_{4}$ and apoA-I $I_{5}$ in their plasma (46). When we have run two dimensional gel electrophoresis on plasma obtained from the three Tangier homozygotes studied in this report we have observed a similar pattern as that reported by Zannis et al. (46). However, the Tangier apoA-I used in our metabolic studies was isolated from the $1.21-\mathrm{g} / \mathrm{ml}$ supernate (i.e., the lipoprotein fraction) following ultracentrifugation of Tan- gier plasma. This Tangier apoA-I preparation contained apoA- $\mathrm{I}_{4}$ and apoA-I $\mathrm{I}_{5}$ as its major isoforms, similar to normal apoA-I (45). These data suggest that ultracentrifugation may selectively remove apoA- $I_{2}$ and apoA- $\mathrm{I}_{3}$ from plasma lipoproteins especially at low apoA-I and HDL concentrations. We cannot exclude the possibility that the in vivo kinetic differences observed between apoA-I $\mathrm{I}_{\text {Tangier }}$ and normal apoA-I may

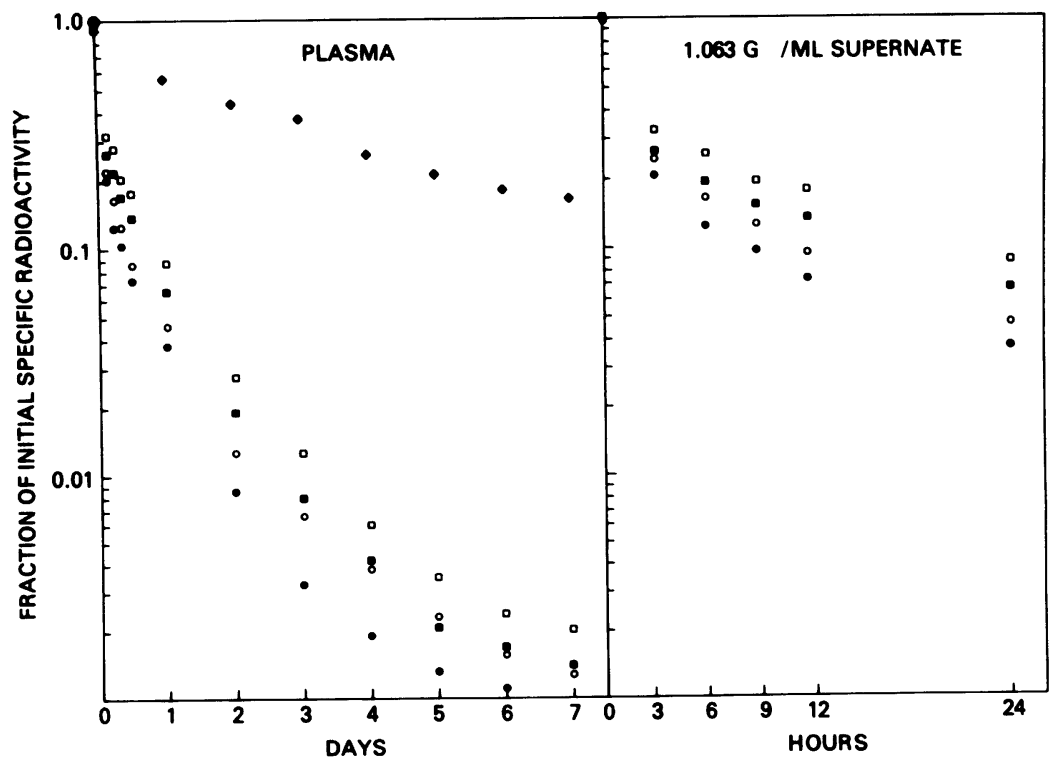

Figure 3 Specific radioactivity decay in plasma (left panel) and $1.063-\mathrm{g} / \mathrm{ml}$ supernate (right

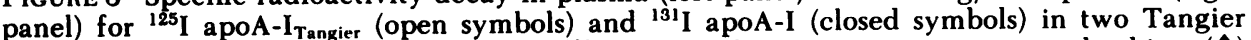
homozygotes are shown. A representative ${ }^{131} \mathrm{I}$ apoA-I plasma curve in one normal subject $(\diamond)$ is also shown. 


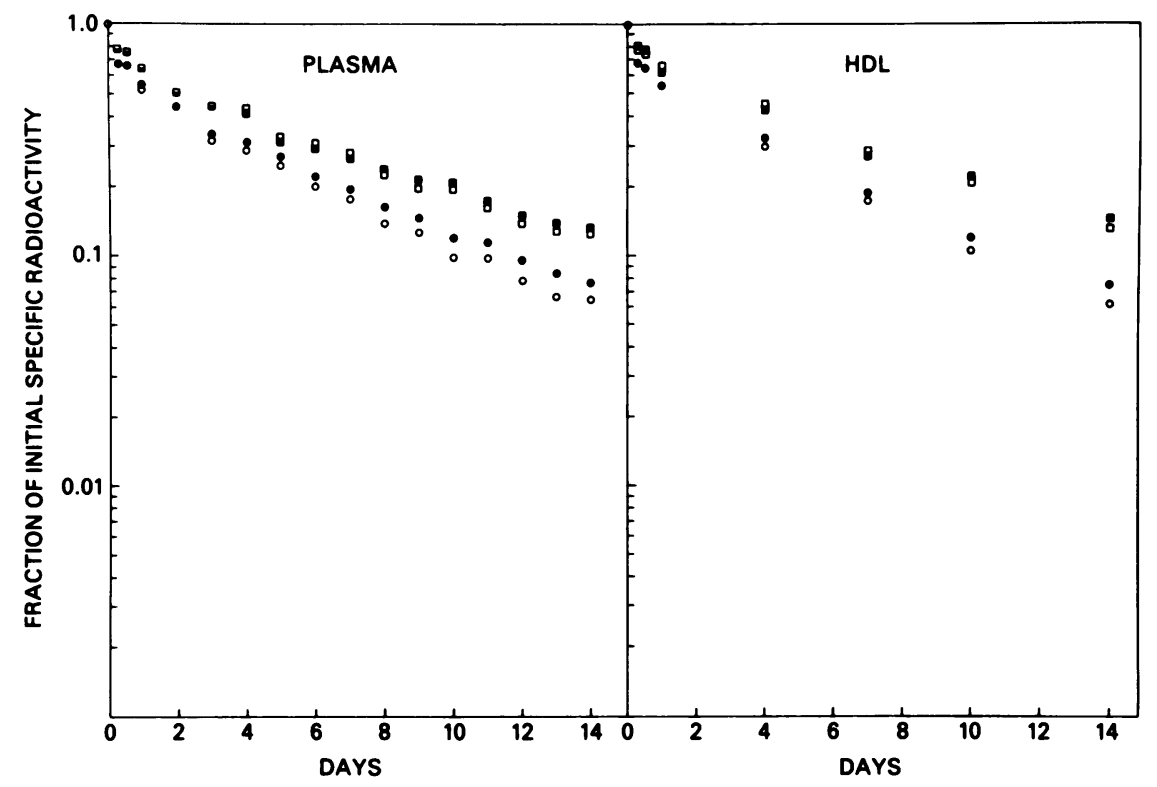

Figure 4 Specific radioactivity curves in plasma (left panel) and HDL $(d, 1.063-1.21 \mathrm{~g} / \mathrm{ml}$,

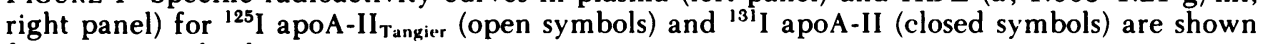
for two normal subjects.

be due to differences in the radioiodination of the various apoA-I isoforms. Additional research is required to precisely determine the nature of the differences between the apoA-I isoforms in normal and Tangier plasma, and to elucidate the exact defect in Tangier apoA-I.

The data are consistent with the concept that Tangier apoA-I is structurally and metabolically different from normal apoA-I, and we therefore have designated this apolipoprotein as apoA-I $\mathrm{I}_{\text {Tangier }}$. In homozygotes the specific activity decay of normal and apoA-I $I_{\text {Tangier }}$ were similar, possibly because the normal apoA-I associated with abnormal lipoproteins, containing apoA-I ${ }_{\text {Tangier }}$. Early work by Lux et al. (48) suggested that Tangier homozygotes had abnormal HDL constituents, but these workers were unable to detect any significant differences in the amino acid composition between normal and Tangier apoA-I, possibly because the apoA-I amino acid sequence was not known at that time. In contrast to apoA-I $\mathrm{I}_{\text {Tangier }}$, our data indicate that Tangier apoA-II appears to be functionally and metabolically identical to normal apoA-II. Both amino acid compositional data (45) as well as the kinetic studies with normal and Tangier apoA-II support this view.

In our view the abnormal apoA-I found in Tangier homozygotes results in the formation of abnormal apoA-I and apoA-II containing lipoproteins as found in the chylomicron, VLDL, LDL, and HDL density regions $(17-19,23-28,49)$. These particles may arise not because of the inability of apoA-I $\mathrm{I}_{\text {Tangier }}$ to bind to lipid, but possibly because lipoproteins containing this apolipoprotein are not normally catabolized and are rapidly cleared from the circulation by reticuloendothelial cells $(5,19,24)$. These alterations result in cholesterol ester deposition in these cells, striking hypercatabolism of apoA-I and apoA-II, and a marked deficiency of HDL. The data presented are consistent with the concepts that the lipoprotein abnormalities seen in Tangier disease are due to an abnormal apoAI (apoA-I Tangier ), and that normal apoA-I is essential for HDL formation (50).

\section{ACKNOWLEDGMENTS}

We wish to thank Mr. Raymond Farkas and staff at the National Institutes of Health Radiopharmacy for assistance in the preparation of radioiodinated lipoproteins and apolipoproteins, Dr. Donald Hochstein of the Bureau of Biologics for pyrogen testing of tracers, Mrs. Elaine Offutt, NIH Nutrition Department, for dietary consultation and services, and Mrs. Exa Murray for assistance in the preparation of the manuscript.

\section{REFERENCES}

1. Fredrickson, D. S., P. H. Altroccchi, L. V. Avioli, D. S. Goodman, and H. C. Goodman. 1968. Tangier disease. Ann. Intern. Med. 27: 165-174.

2. Fredrickson, D. S. 1965. The inheritance of high density lipoprotein deficiency (Tangier disease). J. Clin. Invest. 44: 228-237.

3. Schaefer, E. J., L. A. Zech, D. E. Schwartz, and H. B. Brewer, Jr. 1980. Coronary heart disease prevalence and 
clinical features in familial high density lipoprotein deficiency (Tangier disease). Ann. Intern. Med. 93: 261266.

4. Herbert, P. M., A. M. Gotto, Jr., and D. S. Fredrickson. 1978. Familial lipoprotein deficiency. In The Metabolic Basis off Inherited Disease. 4th edition. J. B. Stanbury, J. B. Wyngaarden, and D. S. Fredrickson, editors. McGraw-Hill Book Co., New York. 544-588.

5. Ferrans, V. J., and D. S. Fredrickson. 1975. The pathology of Tangier disease: a light and electron microscopic study. Am. J. Pathol. 78: 101-158.

6. Waldorf, D. S., R. I. Levy, and D. S. Fredrickson. 1967. Cutaneous cholesteryl ester deposition in Tangier disease. Arch. Dermatol. 95: 161-166.

7. Chu, F. C., T. Kuwabara, P. G. Cogan, E. J. Schaefer, and $H$. B. Brewer, Jr. 1979. Ocular manifestations of familial high density lipoprotein deficiency (Tangier disease). Arch. Ophthalmol. 97: 1926-1928.

8. Katz, S. S., D. M. Small, J. G. Brook, and R. S. Lees. 1977. The storage lipids in Tangier disease. A physical chemical study. J. Clin. Invest. 59: 1045-1054.

9. Kostner, T., and P. Alaupovic. 1972. Studies of the composition and structure of plasma lipoproteins: separation and quantification of lipoprotein families occurring in high density lipoproteins of human plasma. Biochemistry. 11: 3419-3428.

10. Schaefer, E. J., D. M. Foster, L. L. Jenkins, F. T. Lindgren, M. Berman, R. I. Levy, and H. B. Brewer, Jr. 1979. The composition and metabolism of high density lipoprotein subfractions. Lipids. 14: 511-522.

11. Barr, D. P., E. M. Russ, and H. A. Eder. 1951. Protein lipid relationships in human plasma. II. In atherosclerosis and related conditions. Am. J. Med. 11: 480-492.

12. Miller, G. J., and N. F. Miller. 1975. Plasma-high density lipoprotein concentration and development of ischemic heart disease. Lancet. I: 16-20.

13. Rhoads, G., C. L. Gulbrandsen, and A. Kagan. 1976. Serum lipoproteins and coronary heart disease in a population study of Hawaii Japanese men. N. Engl. J. Med. 294: 293-295.

14. Castelli, W., J. T. Doyle, T. Gordon, C. G. Hames, M. Hjortland, S. B. Hulley, A. Kagan, and W. J. Zukel. 1977. HDL cholesterol and other lipids in coronary heart disease. The Cooperative Lipoprotein Phenotyping Study. Circulation. 55: 767-772.

15. Scanu, A. J., J. Toth, C. Edelstein, and E. Stiller. 1969. Fractionation of human serum high density lipoprotein in urea solutions: evidence of polypeptide heterogenity. Biochemistry. 8: 3309-3316.

16. Shore, B., and V. Shore. 1969. Isolation and characterization of polypeptides of human serum lipoproteins. Biochemistry. 8: 4510-4516.

17. Henderson, L. O., P. N. Herbert, D. S. Fredrickson, and R. J. Heinen. 1978. Abnormal concentration and anomalous distribution of apolipoprotein A-I in Tangier disease. Metab. Clin. Exp. 27: 165-174.

18. Assmann, G., P. N. Herbert, and D. S. Fredrickson. 1977. Isolation and characterization of an abnormal high density lipoprotein in Tangier disease. J. Clin. Invest. 60: 242-252.

19. Schaefer, E. J., C. B. Blum, R. I. Levy, L. L. Jenkins, P. Alaupovic, D. M. Foster, and H. B. Brewer, Jr. 1978. Metabolism of high density apolipoproteins in Tangier disease. N. Engl. J. Med. 299: 905-910.

20. Curry, M. D., P. Alaupovic, and C. A. Suenram. 1976. Determination of apolipoprotein $\mathrm{A}$ and its constitutive
A-I and A-II polypeptides by separate electroimmunoassays. Clin. Chem. 22: 315-322.

21. Cheung, M. C., and J. J. Albers. 1977. The measurement of apolipoprotein A-I and A-II levels in men and women by immunoassay. J. Clin. Invest. 60: 43-50.

22. Schonfeld, G., and B. Pfleger. 1974. The structure of high density lipoproteins and the level of apolipoprotein A-I in plasma as determined by radioimmunoassay. $J$. Clin. Invest. 54: 236-246.

23. Heinen, R. J., P. N. Herbert, D. S. Fredrickson, T. Forte, and F. T. Lindgren. 1978. Properties of plasma very low and low density lipoproteins in Tangier disease. J. Clin. Invest. 61: 120-132.

24. Herbert, P. N., T. Forte, R. J. Heinen, and D. S. Fredrickson. 1978. Tangier disease: one explanation of lipid storage. N. Engl. J. Med. 299: 579-521.

25. Schaefer, E. J., L. L. Jenkins, and H. B. Brewer, Jr. 1978. Human chylomicron apolipoprotein metabolism. Biochem. Biophys. Res. Commun. 80: 405-412.

26. Schaefer, E. J., and H. B. Brewer, Jr. 1978. Tangier disease: a defect in the conversion of chylomicrons to high density lipoproteins. Clin. Res. 26: 532a. (Abst.)

27. Assmann, G., A. Capurso, E. Smootz, and U. Wellner. 1978. Apoprotein A metabolism in Tangier disease. Atherosclerosis. 30: 321-332.

28. Schaefer, E. J., D. W. Anderson, L. A. Zech, F. T. Lindgren, T. J. Bronzert, E. A. Rubalcaba, and H. B. Brewer, Jr. 1981. Metabolism of high density lipoprotein subfractions and constituents in Tangier disease following the infusion of high density lipoproteins. J. Lipid Res. 22: 217-228.

29. Hoffman, H. N., and D. S. Fredrickson. 1965. Tangier disease (familial high density lipoprotein deficiency). Clinical and genetic features in two adults. Am. J. Med. 39: 582-593.

30. Manual of Laboratory Operations, Lipid Research Clinics Program. 1974. Lipid and Lipoprotein Analysis. Government Printing Office, Washington, DC DHEW Publication No. 75-625 National Institutes of Health.

31. Auto Analyzer Manual, Technicon Instruments Tarrytown, NY. 1974. p. 345

32. Schaefer, E. J., R. I. Levy, D. W. Anderson, R. N. Danner, H. B. Brewer, Jr., and W. C. Blackwelder. 1978. Plasma triglycerides in regulation in H.D.L. cholesterol levels. Lancet. II: 391-393.

33. Havel, R. J., H. A. Eder, and J. H. Bragdon. 1955. The distribution and chemical composition of ultracentrifugally separated lipoproteins in human serum. J. Clin. Invest. 34: 1345-1353.

34. Lowry, O. H., N. J. Rosebrough, A. L. Farr, and R. J. Randall. 1951. Protein measurement with the Folin phenol reagent. J. Biol. Chem. 193: 165-275.

35. Chalvardjian, A., and E. Rudnicki. 1970. Determination of lipid phosphorus in the nanomolar range. Anal. Biochem. 36: 225-226.

36. Folch, J., M. Lees, and G. H. Sloan-Stanley. 1957. A simple method for the isolation and purification of total lipids from animal tissues. J. Biol. Chem. 226: 497-509.

37. Brewer, H. B., Jr., T. Fairwell, A. Larue, R. Ronan, A. Houser, and T. Bronzert. 1978. The amino acid sequence of human apoA-I, an apolipoprotein isolated from high density lipoproteins. Biochem. Biophys. Res. Commun. 80: 623-630.

38. Brewer, H. B., Jr., S. E. Lux, R. Ronan, and K. M. John. 1972. Amino acid sequence of human apoLp-Gln-II (apoA-II), an apolipoprotein isolated from the high den- 
sity lipoprotein complex. Proc. Natl. Acad. Sci. USA. 69: 1304-1308.

39. McFarlane, A. D. 1978. Efficient trace-labelling of proteins with iodine. Nature (Lond.). 182: 53-00.

40. Weber, K., and M. Osborn. 1969. The reliability of molecular weight determination by dodecyl sulfate polyacrylamide gel electrophoresis. J. Biol. Chem. 244: 4406-4412.

41. Berman, M., and M. F. Weiss. 1978. SAAM Manual. U.S. DHEW publication 75-180, National Institutes of Health.

42. Rescigno, A., and E. Gurpide. 1973. Estimation of average times of residence, recycle, and interconversion of blood-borne compounds using tracer methods. J. Clin. Endocrinol. Metab. 36: 263-276.

43. Alaupovic, P., E. J. Schaefer, W. J. McConathy, J. D. Fesmire, and H. B. Brewer, Jr. 1981. Plasma apolipoprotein concentrations in familial apolipoprotein A-I and A-II deficiency (Tangier disease). Metab. Clin. Exp. 30: 805-809.

44. Shepherd, J., J. R. Patsch, C. J. Packard, A. M. Gotto, Jr., and O. D. Taunton. 1978. Dynamic properties of human high density lipoprotein apoproteins. J. Lipid Res. 19: 383-389.
45. Kay, L. L., R. Ronan, E. J. Schaefer, and H. B. Brewer, Jr. 1981. Tangier disease: a structural defect in apoli-

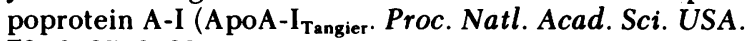
79: 2485-2489.

46. Zannis, V. I., A. M. Lees, R. S. Lees, and J. L. Breslow. 1982. Abnormal apoA-I isoprotein composition in patients with Tangier disease. J. Biol. Chem. 257: 49784986.

47. Zannis, V. I., D. M. Kurnit, and J. L. Breslow. 1982. Hepatic apoA-I and apoE and intestinal apoA-I are synthesized in precursor isoprotein forms by organ culture of human fetal tissue. J. Biol. Chem. 257: 536-544.

48. Lux, S. E., R. I. Levy, A. M. Gotto, Jr., and D. S. Fredrickson. 1972. Studies on the protein defect in Tangier disease: isolation and characterization of an abnormal high density lipoprotein. J. Clin. Invest. 51: 2505-2519.

49. Glickman, R. M., P. H. R. Green, R. S. Lees, and A. Tall. 1978. Apoprotein A-I synthesis in normal intestinal mucosa and in Tangier disease. N. Engl. J. Med. 299: 14241427.

50. Schaefer, E. J., W. H. Heaton, M. G. Wetzel, and H. B. Brewer, Jr. 1982. Plasma apolipoprotein A-I absence associated with marked reduction of high density lipoproteins and premature coronary artery disease. Arteriosclerosis. 2: 16-26. 